\title{
Lise Öğrencilerinin Okul Tükenmişliklerinin Sosyal Destek ve Çeşitli Değişkenler Açısından İncelenmesi ${ }^{1}$
}

\author{
DOI: $10.26466 /$ opus.552366
}

\section{Selim Gündoğan*}

*Arş. Gör., Niğde Ömer Halisdemir Üniversitesi, Eğt. Bil. Böl., PDR Anabilim Dalı, Niğde/Türkiye

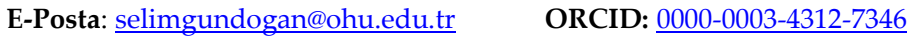

Öz

Çalışmada eğitim yaşamına devam eden öğrencilerde görülen bir durum olan okul tükenmişliği üzerinde sosyal desteğin yordayıcı rolü olup olmadığı ve okul tükenmişliğinin çeşitli değişkenlere göre farklılaşıp farklılaşmadığı incelenmiştir. Çalışma nicel araştırma yöntemlerinden tarama modelinde yürütülen bir çalışmadır. Çalışmanın verileri, örnekleme yöntemlerinden maksimum çeşitlilik örnekleme yöntemi kullanılarak çalışmaya gönüllü olarak katılan 195 kız ve 153 erkek olmak üzere toplam 348 lise öğrencisi üzerinde toplanmıştır. Veriler okul tükenmişliği ölçeği, çok boyutlu algılanan sosyal destek ölçeği ve kişisel bilgi formu kullanılarak toplanmıştır. Elde edilen verilerin analizinde t testi, ANOVA testi, korelasyon ve regresyon analizleri kullanılmıştır. Yapılan analizler sonucunda lise öğrencilerinin okul tükenmişliğinin çeşitli demografik değişkenlere (cinsiyet, liseyi yatıl veya gündüzlü okuma, sınıf) göre farklılaştığı sonucuna ulaşılmıştır. Okul tükenmişliğiyle sosyal destek arasında anlamlı ve negatif yönlü ilişkiler bulunmuştur. Regresyon analizi sonucundaysa; sosyal desteğin okul tükenmişliğinin duygusal tükenme alt boyutunun \%36'sını, duyarsızlaşma alt boyutunun \%32'sini ve düşük kişisel başarı hissi alt boyutunun \%30'unu açıkladığı sonucu elde edilmişstir. Ulaşılan sonuçlar ilgili literatüre göre tartışılmış ve yeni araştırmacılar için önerilerde bulunulmuştur.

Anahtar Kelimeler: ～Lise Öğrencisi, Okul Tükenmişliği, Sosyal Destek

\footnotetext{
${ }^{1}$ Bu çalışma 2.Uluslararası Sosyal Bilimleri Kongresi'nde (USBIK-2019) bildiri özeti olarak sunulmuştur.
} 


\title{
Examination of School Burnout of High School Students in Terms of Social Support and Various Factors
}

\begin{abstract}
In this study, it is examined whether social support has a predictive role on school burnout, which is a condition seen in students who continue their education and whether school burnout differs according to various variables. This study was carried out in the survey model of quantitative research methods. The data of the study was collected on a total of 348 high school students (195 female and 153 male) who participated in the study voluntarily using the maximum diversity sampling method. Data were collected using school burnout scale, multidimensional perceived social support scale and personal information form. In the analysis of the data, $t$ test, ANOVA test, correlation and regression analyzes were used. As a result of the analyzes, it was concluded that high school students' burnout differed according to various demographic variables (gender, high school boarding or daytime reading, class). A significant and negative relationship was found between school burnout and social support. As a result of regression analysis; social support explained 36\% of the emotional exhaustion sub-dimension of school burnout, $32 \%$ of the depersonalization sub-dimension and $30 \%$ of the low personal sense of self-achievement subdimension. The results were discussed according to the related literature and suggestions were made for new researchers.
\end{abstract}

Keywords: High School Student, School Burnout, Social Support 


\section{Giriş}

Bireylerin iş yaşamında pek çok durum ortaya çıkmaktadır. Tükenmişlik iş yaşamında bireyler üzerinde görülen bir durum olarak ortaya çıkan bir kavram olmuştur. 1970'lerden günümüze tükenmişlik kavramı araştırma konusu olagelmiştir (Pines ve Nunes, 2003). Tükenmişlik kavramı ilk olarak Freudenberger (1974) tarafından; enerji, güç ve kaynaklara karşı artan beklentinin sonucunda oluşan yoğun yorgunluk ya da bıkkınlık süreci olarak ortaya çıkan bir durum olarak tanımlanmıştır. Daha sonra başka bir tanımdaysa tükenmişlik: işe bağlı olarak tutum ve davranışlardaki değişikliklerin sonucunda kendini gösteren duygusal tükenmişlik, duyarsızlaşma ve azalan kişisel başarı duygusu olmak üzere üç bileşenden oluşup; süreğen yorgunluk, çaresizlik ve umutsuzluk duyguları, negatif bir benlik algısının gelişmesiyle iş, yaşam ve diğer insanlara yönelik ortaya çıkan olumsuz tutumlarla belirginleşen fiziksel, duygusal ve zihinsel olarak bir tükenme sendromu şeklinde tanımlanmıştır (Maslach, 1981; Maslach ve Jackson, 1981). Başka yazarlara göreyse tükenmişlik, stresle etkin şekilde başa çıkmamanın bir sonucu olarak ortaya çıkan bir durumdur (Friesen ve Sarros, 1989; Torun, 1997; Kaçmaz, 2005). Freudenberger'a göre (1974) tükenmişlik sadece duygusal tükenmişlik boyutunda ele alınmıştır. Tükenmişlik genel olarak ise; literatürde duygusal tükenme, duyarsızlaşma ve düşük kişisel başarı hissi olmak üzere üç boyutta ele alınmaktadır (Maslach ve Jackson 1981; Firth, Micntee, Mckown, ve Britton, 1985; Jackson, Schwab ve Schuler, 1986; Lahoz ve Mason, 1989; Maslach ve Leiter, 1997). Daha sonra araştırmacılarca tükenmişlik kavramının sadece iş yaşamıyla ilgili bir kavram değil okul yaşantısında da ortaya çıkan bir durum olduğu öne sürülmüş ve okul tükenmişliği kavramı literatüre girmiştir (Schaufeli ve diğ., 2002; Gan ve Shang, 2007; Zhang, Gan ve Cham, 2007; Salmela-Aro, Kiuru, Leskinen ve Nurmi, 2009; Parker ve Salmela-Aro, 2011, Çapri, Gündüz ve Gökçakan, 2011; Aypay, 2011; Kutsal ve Bilge, 2012; Seçer ve Gençdoğan, 2012).

Günümüzde bireylerin yaşantısının bir kısmı eğitim kademelerinde geçmektedir. Türkiye'de okul öncesi ile başlayıp üniversiteye kadar süren eğitim süreci bireylerin ortalama 16 yılını almaktadır. Bu eğitim sürecinde öğrencilerin okula dönük algılarını olumlu yönde etkileyen faktörler çok olduğu gibi; okula dönük algılarını olumsuz yönde etkileyen ve okul 
sürecinden soğutan faktörler de pek fazla olabilmektedir. Öğrencilerin akademik süreçlerini olumsuz yönde etkilemekte olan ve son y1llarda araştırmacılarca çok yönlü olarak araştırma konusu yapılmaya başlanılan kavramlardan birisi de okul tükenmişliğidir (Seçer, 2015).

Okul tükenmiş̧liği kavramı okul ve eğitim yaşantısının öğrencilerden yoğun beklentilerinin sonucunda öğrencileri duygusal, bilişsel ve bedensel olarak yıpratması ya da bitkin düşürmesi olarak tanımlanmaktadır (Aypay ve Eryllmaz 2011; Salmela-Aro, Kiuru, Leskinen, ve Nurmi, 2009). Başka bir tanımda okul tükenmişliği okulun yoğun beklentilerine maruz kalmaları sonucunda öğrencilerin yaşadıkları stresle başa çıkamama durumu olarak tanımlanmaktadır (Aypay, 2011). Akademik beklentilerden kaynaklı olarak bitkin düşme, okula ve okulla ilgili aktivitelere karşı olumsuz bir tutum geliştirme ve etkinliklere katılma isteğinde düşüş okul tükenmişliğinin belli başlı belirtileri olarak ortaya çımaktadır (Seçer, Halmatov ve Ateş, 2013; Seçer 2015).

Yapılan araştırmalar öğrencilerde görülen okul tükenmişliğinin pek çok kavramdan etkilendiğini ve pek çok kavramla ilişkili olduğunu ortaya koymuştur. Yapılan çalışmalarda okul tükenmişliği kavramı öznel iyi oluş (Akpınar, 2016; Aypay ve Eryılmaz, 2011; Sarıcam, 2015; Parker ve Salmela-Aro, 2011), psikolojik uyumsuzluk (Seçer, 2015), mükemmeliyetçilik (Luo, Wang, Zhang ve Chen, 2016), depresyon (Salmela-Aro ve diğ, 2008; Koçak ve Seçer, 2018) psikolojik yardım ihtiyacı (Özgen, 2016) ve çeşitli demografik değişkenler (Gündüz, Çapri ve Gökçakan 2012; Seçer ve Gençdoğan, 2012; Demirel, 2018) açısından ele alınmıştır.

Okul tükenmişliği üzerinde etkisi olan hem bireyden hem de diştan kaynaklı faktörler bulunmaktadır. Okul tükenmişliği üzerinde etkili olan diştan kaynaklı faktörlerden birisi de sosyal destektir. Sosyal destek konusu ile okul tükenmişliği arasındaki ilişkiyi inceleyen çalışmalar bulunmaktadır (Pazin, 2000; Weaver, 2000, Kovach, 2002; Jacobs ve Dodd, 2003; Kutsal ve Bilge, 2012; Çam, Deniz ve Kurnaz, 2014). Bu çalışmaların ortak noktası okul tükenmişliği ile sosyal destek arasında negatif yönde bir ilişki olmasıdır. Bu doğrultudan hareketle sosyal desteğin okul tükenmişliğini azaltıcı rolü olduğu söylenebilir.

Sosyal destek kavramı kuramsal olarak Kurt Lewin'in Alan Kuramı ve davranış tanımına dayanmaktadır (Boldwin, 1967; Akt. Yıldırım, 1998). Sosyal destek kavramı; bireyin mevcut çevresinden gördüğü olumlu 
tepkiler (ilgi, sevgi, güven, sayg1, takdir edilme vb.) ve ihtiyaç duyulan maddi yardım gibi çoğu açıdan bireye destek süreci olarak tanımlanmaktadır (Yıldırım, 2010). Sorias'a (1988) göre sosyal destek kavramı, "sosyal ağın yeterince destekleyici olup olmadığı konusunda kişinin genel bir izlenimi" olarak ele alınmıştır. Sosyal destek kavramına başka bir tanım olarak Cohen ve Syme'in (1985) tanımı verilebilir; bu tanıma göre sosyal destek başkaları bireye tarafından sağlanan kaynaklardır. Sosyal destek kavramı genellikle zorlu veya stres artırıcı durumlarda kişinin ulaşabileceği maddi veya manevi yardım olarak kabul edilmektedir. Sosyal desteği elde eden insanların ihtiyaçları olduğunda güvenebilecekleri kaynaklara (eş, arkadaş, aile gibi) sahip oldukları öne sürülmektedir (Sarason ve Sarason, 1982). Tardy'e (1985) göreyse sosyal desteğin: yönü (alınışı veya verilişi), eğilimi (destek kaynaklarının olması ve kullanılması), desteğin tanımlanması (değerlendirilme yapılması), desteğin hangi içeriğe sahip olduğu (duygusal, bilgisel ve araçsal destek gibi) ve sosyal ağ olmak üzere 5 yönü bulunmaktadır. Cohen ve Wills (1985) sosyal desteğin, duygusal destek, araçsal destek, bilgisel destek ve yaygın destek şeklinde 4 boyutla açıklanması gerektiği fikrini öne sürmüşlerdir. Kutsal ve Bilge'ye (2012) göre öğrencilerde görülen tükenmişlikte öğrencinin kendi gücünün ve isteklerine ek olarak ailenin, arkadaşların ve öğretmenlerin de öğrenciden beklentilerinin dengeli olması, bireyin yakın çevresinin desteğini hissettirmesi ve rehberliği önemli etkenler arasındadır. Bu etkenler okul tükenmişliğini azaltıcı rol üstlenmektedir. Başka bir ifadeyle sosyal desteğin artması okul tükenmişliğini azaltmakta ve öğrencinin eğitim yaşantısının daha verimli geçmesine yol açmaktadır (Kim ve diğ., 2017). Buna ek olarak; sosyal destek kaynaklarının sınırlı olmasının tükenmişliği artırdığı öne sürülmüştür (SalmelaAro, Kiuru ve Nurmi, 2008).

Sonuç olarak; okul tükenmişliğinin öğrenciler arasında yaşanan ve öğrencilerin pek çok özellikler üzerinde olumsuz etkileri olan yaygın bir durum olduğu görülmektedir. Okul tükenmişliği ile negatif yönlü bir ilişkisi olan ve okul tükenmişliğini azaltıcı role sahip olan kavramlardan birinin de ilgili literatürde sosyal destek olduğu görülmektedir (Jacobs ve Dodd, 2003; Kutsal ve Bilge, 2012; Çam, Deniz ve Kurnaz, 2014). Yapılan bu çalışmalarda sosyal desteğin okul tükenmişliğini yordayan bir değişken olduğu görülmektedir. Bu çalışmada da sosyal destek yordayıcı 
değişken olarak ele alınmıştır. Ayrıca okul tükenmişliğinin üzerinde çeşitli demografik değişkenlerin de etkili olduğu görülmektedir (Seçer ve Gençdoğan, 2012; Şeker ve Yavuzer, 2017).

Psikolojik danışmanlık ve rehberlik alanında, okul ortamında ortaya çıkması muhtemel sorunların önlenmesi veya ortaya çıkmış olan sorunların olası kötü sonuçlarının azaltılıp çözüme kavuşturulması önemli bir konudur. Okul tükenmişliğinin okul çağındaki bireylerde yoğun olarak görülen bir sorun alanı olduğu göz önünde bulundurulduğunda bu durum okul tükenmişliğini azaltıcı faktörlerin dikkate alınmasını gerekli kılmaktadır. Bu çalışmada da, okul ortamlarında psikolojik danışmanlık ve rehberlik alanındaki koruyucu ve önleyici müdahelelere 1şık tutması için okul tükenmişliği konusu çalışma konusu olarak belirlenmiştir. Ayrıca ilgili literatüre okul tükenmişliği ile sosyal destek arasındaki ilişkiyi ele alan güncel bir çalışmanın daha kazandırılması, okul tükenmişliğini azaltıcı faktörlerden birisi olan sosyal desteğin bu çalışmada da ele alınarak sosyal desteğin azaltıcı rolünün ortaya konması ve okul tükenmişliği gibi güncel, pek çok araştırmaya konu olmuş bir konunun çeşitli değişkenlere göre farklılaşıp farklılaşmadığının güncel bir çalışmayla daha tekrar incelenmesi amaçlanmıştır. Bu doğrultudan hareketle bu çalışmada aşağıdaki sorulara yanıt aranmıştır:

- Lise öğrencilerinin okul tükenmişlik puanları cinsiyet, sınıf ve liseyi yatılı ya da gündüzlü okuma değişkenlerine göre anlamlı olarak farklılaşmakta mıdır?

- Lise öğrencilerinin okul tükenmişlik puanları ile sosyal destek düzeyleri arasında anlamlı ilişki var mıdır?

- Lise öğrencilerinin okul tükenmişliğinin sosyal destek anlamlı bir yordayıcısı midır?

\section{Yöntem}

Çalışma nicel araştırma yöntemlerinden tarama modelinde yürütülen bir çalışmadır. "Tarama modelleri, geçmişte ya da halen var olan bir durumu var olduğu şekliyle betimlemeyi amaçlayan araştırma yaklaşımı olup; araştırmaya konu olan olay, birey, ya da nesne kendi koşulları içinde ve olduğu gibi tanımlanmaya çalışılır" (Karasar, 2013). 


\section{Çalışma Grubu}

Çalışmanın evrenini Niğde ilinde lise öğrenimine devam eden 19233 lise öğrencisi oluşturmaktadır. Örneklemini "evrende incelenen problemle ilgili olarak kendi içinde benzeşik farklı durumların belirlenerek çalışmanın bu durumlar üzerinde yapılması" olarak tanımlanan (Büyüköztürk, Kılıç-Çakmak, Akgün, Karadeniz ve Demirel, 2014) “amaçsal örneklem yöntemlerinden maksimum çeşitlilik örnekleme yöntemi" kullanılarak seçilen, çeşitli liselerde öğrenimine devam eden 195'i kız ve 153'ü erkek öğrencilerden olmak üzere toplam 348 lise öğrencisi oluşturmuştur.

\section{Veri Toplama Araçları}

Çalışmada elde edilen verileri toplamak için okul tükenmişlik ölçeği, çok boyutlu algılanan sosyal destek ölçeği ve kişisel bilgi formu kullanılmıştır.

\section{Okul Tükenmişliği Ölçeği:}

Ortaokul ve lise öğrencilerinin okul süreçlerinden kaynaklanan tükenmişlik özelliklerini ölçmek amacıyla Salmela-Aro ve ark. (2009) tarafından geliştirilmiş olan ölçeğin, Türkçe'ye uyarlaması Seçer ve ark. (2013) tarafından yapılmıştır. Ölçek toplam 9 madde ve 3 alt boyuttan oluşmaktadır. Bu alt boyutlar; duygusal tükenmişlik, duyarsızlaşma ve düşük kişisel başarı algısıdır. Ölçeğin geçerlik analizleri sonucunda toplam varyansın \% 63.25 varyans açıklamakta olduğu ve üç faktörlü yapısının model uyumunun iyi düzeyde olduğu sonucuna ulaşılmıştır (REMSEA=.06, CFI=.94, TLI=.93). Ölçeğin güvenirlik değerinin .87, test tekrar test güvenirliğinin ise .88 olduğu bulunmuştur. Bu çalışmadaysa; iç tutarlık katsayıları duygusal tükenmişlik alt boyutu için .72, duyarsızlaşma alt boyutu için .82 ve düşük kişisel başarı algısı alt boyutu içinse .74 olarak bulunmuştur. 


\section{Çok Boyutlu Algılanan Sosyal Destek Ölçeği}

Zimet ve ark. (1988) tarafından geliştirilmiş olan Çok Boyutlu Algılanan Sosyal Destek Ölçeği'nin Türk kültürüne uyarlanması Eker, Arkar ve Yaldız (2001) tarafından yapılmıştır. Ölçek 12 madde ve 3 alt boyuttan oluşmaktadır. Bu kapsamda 3 farklı kaynaktan (aile, arkadaş, özel bir insan) algılanan destek ölçeğin alt boyutlarını oluşturmaktadır. Çok Boyutlu Algılanan Sosyal Destek Ölçeği 7'li likert tipinde ve öz bildirime dayalı bir ölçektir. Ölçeğin uyarlama sürecinde güvenirlik geçerlilik analizleri kapsamında Cronbach Alfa katsayısı hesaplanmıştır. Bu kapsamda ölçeğin iç tutarlılık katsayıları ölçeğin geneli için .89; aileden algılanan destek alt boyutunda .85 , arkadaştan algılanan destek alt boyutunda .80 ve özel bir insandan algılanan destek alt boyutunda .82 'dir. Bu çalışmadaysa; iç tutarlık katsayıları ölçeğin geneli için .91; aileden algllanan destek alt boyutunda .89, arkadaştan algilanan destek alt boyutunda .91 ve özel bir insandan algilanan destek alt boyutunda .92 olarak bulunmuştur.

\section{Kişisel Bilgi Formu}

Araştırmacı tarafından katılımcı grubun demografik özelliklerini belirlemek amacıyla kişisel bilgi formu hazırlanmıştır.

\section{İşlem}

Çalışmadaki veriler araştırmacı tarafından katılımcı gruba çalışmanın bilimsel bir amaçla yapıldığı ve katılımın gönüllük esasına dayalı olduğu belirtilerek toplanmıştır. Çalışmaya gönüllü olarak katılan öğrencilere ölçeklerin nasıl doldurulacağı ve katılımcı öğrencilerin birincil bilgilerini paylaşmaması gerektiği araştırmacı tarafından belirtilmiştir. Çalışmada ciddi boşluk bulunan, tam doldurulmamış olan ölçekler çalışmaya dahil edilmemiştir. Çalışma tüm maddeleri eksiksiz olarak doldurulan ölçekler üzerinde yürütülmüştür. 


\section{Verilerin Analizi}

Çalışmada toplanan veriler üzerinde $t$ testi, ANOVA, korelasyon ve regresyon analizleri kullanılarak analizler yapılmıştır. Parametrik testler için ön koşul olan verilerin normal dağılım göstermesi kriteri basıklık ve çarpıklık katsayıları incelenerek kontrol edilmiştir. Basıklık ve çarpıklık katsayısı duygusal tükenme için .633 ve .161, duyarsızlaşma için .773 ve .395, düşük kişisel başarı algısı için .767 ve -.223 , özel bir insandan sosyal destek için -.287 ve -.236, aileden sosyal destek için -.766 ve -.562, arkadaştan sosyal destek için -.641 ve -.569 olarak bulunmuştur. Verilerin normal dağıldığını görülmüş ve ardından analiz aşamasını geçilmiştir (Büyüköztürk, 2007). Ayrıca verilerin etki büyüklükleriyse eta-kare ( $\eta 2$ ) ve Cohen'in d indeksi ile hesaplanmıştır. Cohen (1988) d'nin yorumu için belli kesme noktaları belirlemiştir: etki büyüklükleri $\mathrm{d}=.02$ ' de "küçük", $\mathrm{d}=$ .05 'te "orta" ve $\mathrm{d}=.08$ olduğunda ise "büyük" olarak gruplanmaktadır (Akt. Erkuş 2005). Bu aralıktaki değerlere göre yorum yapılmıştır.

Regresyon analizi içinse gerekli olan ön koşulların da sağlanıp sağlanmadığı kontrol edilmiştir. Regresyon analizi için ön koşullara bakıldığında oto-korelasyon için Durbin Watson istatistiğine bakılmış değerlerin 1.677 ile 1.868 arasında olduğu ve 1.5-2.5 değerleri arasında olma kriterini sağladığı, VIF ve tolerans değerlerinin istenilen aralıkta olduğu, verilerin normal dağılım gösterdiği ve bağımsız değişkenler arası korelasyon $0.80^{\prime}$ den daha yüksek olmaması koşulları sağlandıktan sonra analizler yapılmıştır (Büyüköztürk, 2007). Değişkenler arasındaki ikili korelasyonlar incelendiğinde en yüksek korelasyon değerinin .785 ve .80 'den küçük olduğu bulunmuştur.

\section{Bulgular}

$\mathrm{Bu}$ bölümde lise öğrencilerinin okul tükenmişliğinin cinsiyet ve lise eğitimine yatılı ya da gündüzlü devam etme değişkenine göre $t$ testi sonucuna, sınıf değişkenine göre ANOVA sonucuna ilişkin elde edilen bulgulara yer verilmiştir. Ayrıca lise öğrencilerinin okul tükenmişliği ile sosyal destek düzeyleri arasındaki ilişkiye ait korelasyon analizine ve sosyal desteğin okul tükenmişliğini yoryacılığına ilişkin regresyon 
analizine ilişkin elde edilen sonuçlara yer verilmiştir. Elde edilen sonuçlara ilişkin bulgular aşağıdaki tablolarda verilmiştir.

Tablo 1. Cinsiyet değişkenine göre okul tükenmişliğinin farklılaşıp farklılaşmadı̆̆ına dair t testi sonucu

\begin{tabular}{|c|c|c|c|c|c|c|c|}
\hline \multicolumn{3}{|c|}{$\overline{\text { Alt Boyutlar Cinsiyet } \mathbf{N}}$} & \multirow{2}{*}{$\begin{array}{l}\mathbf{X} \\
10,48\end{array}$} & \multirow{2}{*}{$\begin{array}{l}\text { S.s } \\
3,83\end{array}$} & \multirow{2}{*}{$\begin{array}{l}\mathbf{t} \\
2,867\end{array}$} & \multirow{2}{*}{$\frac{\mathrm{p}}{, 004^{*}}$} & \multirow{2}{*}{$\begin{array}{l}\text { E.B. d } \\
, 309\end{array}$} \\
\hline Duygusal tü & $-\mathrm{K}_{12}$ & 195 & & & & & \\
\hline kenme & Erkek & 153 & 9,33 & 3,53 & & & \\
\hline$\overline{\text { Duy- }}$ & $\mathrm{K}_{1 Z}$ & 195 & 7,17 & 3,75 & 1,822 & 069 & 196 \\
\hline arsızlaşma & Erkek & 153 & 6,47 & 3,26 & & & \\
\hline Düşük kişise & $1 K_{1 z}$ & 195 & 4,97 & 2,30 & 2,928 &, $004^{*}$ & ,316 \\
\hline başarı hissi & Erkek & 153 & 4,26 & 2,13 & & & \\
\hline
\end{tabular}

${ }^{*} \mathrm{P}<.05$, (E.B.= etki büyüklüğ̈̈)

Tablo incelendiğinde lise öğrencilerinin okul tükenmişlik puan ortalamasının duygusal tükenme $(\mathrm{t}=2,867 ; \mathrm{p}<.05)$ ve düşük kişisel başarı hissi $(\mathrm{t}=2,928 ; \mathrm{p}<.05)$ alt boyutlarında cinsiyet değişkenine göre anlamlı olarak farklılaştığ 1 görülmektedir. Bu sonuca göre; kız öğrencilerin 2 alt boyutta da erkeklere göre daha çok okul tükenmişliği yaşadığı söylenebilir. Etki büyüklükleri incelendiğindeyse cinsiyet değişkeninin okul tükenmişliğinin duygusal tükenme ve düşük kişisel başarı hissi alt boyutları üzerinde orta büyüklükte, duyarsızlaşma alt boyutu üzerinde küçük büyüklükte etkiye sahip olduğu söylenebilir.

Tablo 2. Liseyi yatılı ya da gündüzlü olarak okuma değişkenine göre okul tükenmişliğinin farklılaşıp farklılaşmadığına dair $t$ testi sonucu

\begin{tabular}{llllllll}
\hline & $\begin{array}{l}\text { Liseyi okuma } \\
\text { durumu }\end{array}$ & $\mathbf{N}$ & $\mathbf{X}$ & S.s & $\mathbf{t}$ & $\mathbf{p}$ & E.B.d \\
\hline Duygusal boyutlar & Gündüzlü & 261 & 10,27 & 3,76 & 2,583 &, $010^{*}$ & .319 \\
tükenme & Yatılı & 87 & 9,09 & 3,56 & & & \\
\hline Duyarsızlaşma & Gündüzlü & 261 & 7,22 & 3,66 & 3,265 &, $001^{*}$ & .404 \\
& Yatılı & 87 & 5,80 & 2,99 & & & \\
\hline Düşük kişisel & Gündüzlü & 261 & 4,88 & 2,30 & 3,151 &, $002^{*}$ & .390 \\
başarı hissi & Yatılı & 87 & 4,01 & 1,97 & & & \\
\hline
\end{tabular}

${ }^{*} \mathrm{P}<.05$

Tablo incelendiğinde lise öğrencilerinin okul tükenmişlik puan ortalamasının duygusal tükenme $(t=2,583 ; \mathrm{p}<.05)$, duyarsızlaşma $(t=3,265 ; \mathrm{p}<.05)$ 
ve düşük kişisel başarı hissi $(\mathrm{t}=3,151 ; \mathrm{p}<.05)$ alt boyutlarında liseyi yatılı ve gündüzlü olarak okuma değişkenine göre anlamlı olarak farklılaştığı görülmektedir. Bu sonuca göre; liseyi gündüzlü olarak okumakta olan öğrencilerin tüm alt boyutlarda yatılı olarak lise eğitimine devam etmekte olanlara göre daha çok okul tükenmişliği yaşadığı söylenebilir. Etki büyüklükleri incelendiğindeyse liseyi yatılı ya da gündüzlü okuma değişkeninin okul tükenmişliğinin 3 alt boyutu üzerinde de orta büyüklükte etkiye sahip olduğu söylenebilir.

Tablo 3. Sınıf değişkenine göre okul tükenmişliğinin farklılaşıp farklılaşmadı̆̆ına dair ANOVA testi sonucu

\begin{tabular}{|c|c|c|c|c|c|c|c|c|c|}
\hline $\begin{array}{l}\text { Alt } \\
\text { boyutlar }\end{array}$ & Sinif & $\mathbf{N}$ & $X$ & S.s. & Sd & F & $\mathrm{p}$ & $\begin{array}{l}\text { Anlamli } \\
\text { fark }\end{array}$ & E.B. $\eta^{2}$ \\
\hline \multirow{4}{*}{$\begin{array}{l}\text { Duygusal } \\
\text { tükenme }\end{array}$} & $\begin{array}{l}9 . \\
\text { sinuf }\end{array}$ & 48 & 8,50 & 2,94 & \multirow{4}{*}{$3 / 344$} & \multirow{4}{*}{6,666} & \multirow{4}{*}{, $000^{*}$} & \multirow{4}{*}{ A-D, BD } & \multirow{4}{*}{,055 } \\
\hline & $\begin{array}{l}10 . \\
\text { sinif }\end{array}$ & 83 & 9,19 & 3,48 & & & & & \\
\hline & $\begin{array}{l}11 . \\
\text { sinif }\end{array}$ & 83 & 10,19 & 3,43 & & & & & \\
\hline & $\begin{array}{l}12 . \\
\text { sinif }\end{array}$ & 134 & 10,87 & 4,09 & & & & & \\
\hline \multirow{4}{*}{$\begin{array}{l}\text { Duy- } \\
\text { arsizlaşma }\end{array}$} & $\begin{array}{l}9 . \\
\text { sinif }\end{array}$ & 48 & 5,35 & 2,50 & \multirow{4}{*}{$3 / 344$} & \multirow{4}{*}{6,047} & \multirow{4}{*}{, $001^{*}$} & \multirow{4}{*}{ A-D } & \multirow{4}{*}{,050 } \\
\hline & $\begin{array}{l}10 . \\
\text { sinif }\end{array}$ & 83 & 6,48 & 3,41 & & & & & \\
\hline & $\begin{array}{l}11 . \\
\text { sinif }\end{array}$ & 83 & 6,75 & 3,71 & & & & & \\
\hline & $\begin{array}{l}12 . \\
\text { sinif }\end{array}$ & 134 & 7,71 & 3,66 & & & & & \\
\hline \multirow{4}{*}{$\begin{array}{l}\text { Düşük } \\
\text { kişisel } \\
\text { başarı hissi }\end{array}$} & $\begin{array}{l}9 . \\
\text { sinif }\end{array}$ & 48 & 3,89 & 1,65 & \multirow{4}{*}{$3 / 344$} & \multirow{4}{*}{5,515} & \multirow{4}{*}{, $001^{*}$} & \multirow{4}{*}{ A-D, BD } & \multirow{4}{*}{,046 } \\
\hline & $\begin{array}{l}10 . \\
\text { sinif }\end{array}$ & 83 & 4,37 & 2,21 & & & & & \\
\hline & $\begin{array}{l}11 . \\
\text { sinif }\end{array}$ & 83 & 4,48 & 2,28 & & & & & \\
\hline & $\begin{array}{l}12 . \\
\text { sinif }\end{array}$ & 134 & 5,23 & 2,34 & & & & & \\
\hline
\end{tabular}

${ }^{*} \mathrm{P}<.05(\mathrm{~A}=9$. sinif, $\mathrm{B}=10$. sinif, $\mathrm{C}=11$. sinif, $\mathrm{D}=12$. Sinıf $)$

Tablo incelendiğinde lise öğrencilerinin okul tükenmişlik puan ortalamasının duygusal tükenme $(\mathrm{F}=6,666 ; \mathrm{p}<.05)$, duyarsızlaşma $(\mathrm{F}=6,047$; $\mathrm{p}<.05)$ ve düşük kişisel başarı hissi $(\mathrm{F}=5,515 ; \mathrm{p}<.05)$ alt boyutlarında sınıf 
değişkenine göre anlamlı olarak farklılaştı̆̆ görülmektedir. Gruplar arası farkın kaynağını belirlemek için TUKEY testi yapılmıştır.

Duygusal tükenme alt boyutunda 9. sinif ile 12. sinif ve 10. sinif ile 12. sinıf öğrencileri arasında okul tükenmişliğinin anlamlı olarak farklılaştığı sonucuna ulaşılmıştır. Duyarsızlaşma alt boyutunda 9. sınıf ile 12. sınıf öğrencileri arasında okul tükenmişliğinin anlamlı olarak farklılaştığı sonucuna ulaşılmıştır. Düşük kişisel başarı hissi alt boyutundaysa 9. sinıf ile 12. sınıf ve 10. sınıf ile 12. sınıf öğrencileri arasında okul tükenmişliğinin anlamlı olarak farklılaştı̆g 1 sonucuna ulaşılmıştır. Genel olarak 3 alt boyutta da okul tükenmişlik puan ortalamasının alt sinuflardan üst sinıflara doğru artmakta olduğu görülmektedir. Etki büyüklükleri incelendiğindeyse sınıf değişkeninin okul tükenmişliğini \%4 ile \%5 oranında açıkladığı söylenebilir.

Tablo 4. Okul tükenmişliğiyle algılanan sosyal destek arasındaki ilişkiye dair korelasyon analizi sonucu

\begin{tabular}{lllllll}
\hline & 1 & 2 & 3 & 4 & 5 & 6 \\
\hline 1. Duygusal tükenme & 1 & & & & & \\
2. Duyarsızlaşma &, $780^{* *}$ & 1 & & & & \\
3. Düşük kişisel başarı hissi &, $763^{* *}$ &, $785^{* *}$ & 1 & & & \\
4.Özel bir insandan sosyal destek &,$- 342^{* *}$ &,$- 327^{* *}$ &,$- 332^{* *}$ & 1 & & \\
5. Aileden sosyal destek &,$- 588^{* * *}$ &,$- 547^{* *}$ &,$- 530^{* *}$ &, $488^{* *}$ & 1 & \\
6.Arkadaştan sosyal destek &,$- 427^{* *}$ &,$- 435^{* *}$ &,$- 408^{* *}$ &, $706^{* *}$ &, $574^{* *}$ & 1 \\
\hline${ }^{* *} \mathrm{P}<.01$ & & & & & &
\end{tabular}

Tablo incelendiğinde yapılan korelasyon analizi sonucunda okul tükenmişliğinin alt boyutları duygusal tükenme, duyarsızlaşma ve düşük kişisel başarı hissi ile sosyal desteğin alt boyutları özel bir insandan algılanan sosyal destek, aileden sosyal destek ve arkadaştan sosyal destek arasında anlamlı ve negatif yönde bir ilişkinin olduğu görülmektedir. Ayrıca okul tükenmişliği ile sosyal destek arasındaki ilişkilerin $.80^{\prime}$ den küçük olduğu ve regresyon analizi için bir ön koşul olan çoklu bağlantı probleminin olmadığ 1 görülmektedir (Büyüköztürk, 2007). 
Tablo 5. Sosyal desteğin okul tükenmişliğini yordayıcılığına ilişkin regresyon analizi sonucu

\begin{tabular}{|c|c|c|c|c|c|c|c|}
\hline $\begin{array}{l}\text { Bağımlı } \\
\text { değişkkenler }\end{array}$ & $\begin{array}{l}\text { Yordayıcı } \\
\text { Değişkenler }\end{array}$ & B & $\begin{array}{l}\text { Standart } \\
\text { Hata }\end{array}$ & $\beta$ & $t$ & $\mathbf{R}^{2}$ & $\mathrm{p}$ \\
\hline \multirow{4}{*}{$\begin{array}{l}\text { Duygusal } \\
\text { Tükenme }\end{array}$} & Sabit & 17,229 & ,569 & & 30,257 & \multirow{4}{*}{,36 } &, $000^{* *}$ \\
\hline & $\begin{array}{l}\text { Özel bir } \\
\text { insandan } \\
\text { sosyal destek }\end{array}$ & ,002 & ,028 & ,004 & 059 & & ,953 \\
\hline & $\begin{array}{l}\text { Aileden sosyal } \\
\text { destek }\end{array}$ &,- 275 & ,029 &,- 511 & $-9,593$ & &, $000^{* *}$ \\
\hline & $\begin{array}{l}\text { Arkadaştan } \\
\text { sosyal destek }\end{array}$ &,- 075 & ,036 &,- 136 & $-2,072$ & &, $039^{*}$ \\
\hline \multirow{4}{*}{ Duyarsızlaşma } & Sabit & 13,527 & ,556 & & 24,348 & \multirow{4}{*}{32} &, $000^{* *}$ \\
\hline & $\begin{array}{l}\text { Özel bir } \\
\text { insandan } \\
\text { sosyal destek }\end{array}$ & ,015 & ,028 & ,034 & ,544 & &, 587 \\
\hline & $\begin{array}{l}\text { Aileden sosyal } \\
\text { destek }\end{array}$ &,- 229 & ,028 &,- 448 & $-8,185$ & &, $000^{* *}$ \\
\hline & $\begin{array}{l}\text { Arkadaştan } \\
\text { sosyal destek }\end{array}$ &,- 106 & ,035 &,- 202 & $-2,994$ & &, $003^{* *}$ \\
\hline \multirow{4}{*}{$\begin{array}{l}\text { Düşük kişisel } \\
\text { başarı hissi }\end{array}$} & Sabit & 8,699 & 359 & & 24,210 & \multirow{4}{*}{,30 } &, $000^{* *}$ \\
\hline & $\begin{array}{l}\text { Özel bir } \\
\text { insandan } \\
\text { sosyal destek }\end{array}$ &,- 004 & ,018 &,- 015 &,- 240 & &, 811 \\
\hline & $\begin{array}{l}\text { Aileden sosyal } \\
\text { destek }\end{array}$ & -142 & ,018 & -439 & $-7,876$ & &, $000^{* *}$ \\
\hline & $\begin{array}{l}\text { Arkadaştan } \\
\text { sosyal destek }\end{array}$ &,- 048 & ,023 & -,145 & $-2,104$ & &, $036^{*}$ \\
\hline
\end{tabular}

${ }^{*} \mathrm{P}<.05,{ }^{* *} \mathrm{p}<.01$

Tablo incelendiğinde yapılan çoklu regresyon analizi sonucunda sosyal desteğin lise öğrencilerinin okul tükenmişliğinin "duygusal tükenme" alt boyutunun \%36'sını ( $\mathrm{p}<.001)$ açıklamakta olduğu görülmektedir. Sosyal desteğin alt boyutlarından aileden sosyal destek $(\beta=-, 511 ; \mathrm{p}<.01)$ ve arkadaştan sosyal destek $(\beta=-, 136 ; p<.05)$ alt boyutlarının anlamlı birer yordayıcı olduğu görülürken, özel bir insandan sosyal destek $(\beta=, 004$; p>.05) alt boyutunun anlamlı bir yordayıcı olmadığı görülmektedir.

Tablo incelendiğinde yapılan çoklu regresyon analizi sonucunda sosyal desteğin lise öğrencilerinin okul tükenmişliğinin "duyarsızlaşma" alt boyutunun \%32'sini ( $<<.001)$ açıklamakta olduğu görülmektedir. Sosyal desteğin alt boyutlarından aileden sosyal destek $(\beta=-, 448 ; \mathrm{p}<.01)$ 
ve arkadaştan sosyal destek $(\beta=-, 202 ; \mathrm{p}<.01)$ alt boyutlarının anlamlı birer yordayıcı olduğu görülürken, özel bir insandan sosyal destek $(\beta=, 034$; p>.05) alt boyutunun anlamlı bir yordayıcı olmadığı görülmektedir.

Yine tablo incelendiğinde yapılan çoklu regresyon analizi sonucunda sosyal desteğin lise öğrencilerinin okul tükenmişliğinin "düşük kişisel başarı hissi" alt boyutunun \%30'unu ( $<<.001)$ açılamakta olduğu görülmektedir. Sosyal desteğin alt boyutlarından aileden sosyal destek ( $\beta$ $=-, 439 ; \mathrm{p}<.01)$ ve arkadaştan sosyal destek $(\beta=-, 145 ; \mathrm{p}<.05)$ alt boyutlarının anlamlı birer yordayıcı olduğu görülürken, özel bir insandan sosyal destek $(\beta=-, 015 ; p>.05)$ alt boyutunun anlamlı bir yordayıcı olmadığı görülmektedir.

\section{Sonuç, Tartışma ve Öneriler}

Çalışmada lise öğrencilerinde çokça görülen bir durum olan ve pek çok değişkenin üzerinde etkisi olan okul tükenmişliği kavramının sosyal destek ve çeşitli değişkenler açısından incelenmesi amaçlanmıştır. Çalışmada cevap aranan ilk araştırma problemi lise öğrencilerinin okul tükenmişliğinin cinsiyete göre farklılaşıp farklılaşmadığı sorusudur. Çalışmada lise öğrencilerinin okul tükenmişliğinin cinsiyet değişkenine göre duygusal tükenme ve düşük kişisel başarı algısı alt boyutlarında kızların erkeklere göre daha çok okul tükenmişliği yaşadığı sonucuna ulaşılmıştır. Çalışmada elde edilen bulgu literatürde bazı çalışmalarla tutarlılık göstermektedir (Özbakır, 2015; Demir, 2015; Özdemir, 2015; Özgen, 2016; Çakmak ve Şahin, 2017). Bazı çalışmalarda ise erkeklerin kızlara göre daha çok okul tükenmişliği yaşadığı sonucuna ulaşılmıştır (Salmela-Aro ve diğ., 2008; Seçer ve Gençdoğan, 2012; Salmela-Aro ve Tynkkynen, 2012; Çapulcuoğlu ve Gündüz, 2013; Acar ve Çakır, 2015; Aypay ve Sever, 2015; Yavuzer ve Şeker, 2017). Bu bulgularsa, çalışmada ulaşılan bulguyla paralellik göstermeyen bulgulardır. Bu çalışmada elde edilen bulguya göre aile veya çevrenin kız öğrencilerden okulla ilgili süreçlerde daha çok beklenti içerisinde olmasının kızların daha çok okul tükenmişliği yaşamasında etkili olduğu düşünülebilir.

Çalışmada lise öğrencilerinin okul tükenmişliğinin lisede gündüzlü ya da yatılı olarak öğrenim görmelerine göre farklılaşıp farklılaşmadığı incelenmiştir. Üç alt boyutta da liseye gündüzlü olarak öğrenimine devam 
etmekte olan öğrencilerin yatılılara göre daha çok okul tükenmişliği yaşadığı sonucuna ulaşılmıştır. Acar ve Çakır'ın (2015) çalışmasında okul tükenmişliğinin ödev yapmaktan tükenme alt boyutunda gündüzlü olarak liseye devam etmekte olanların pansiyonda kalan öğrencilere göre daha çok okul tükenmişliği yaşadığı sonucu elde edilmiştir. Bu bulgu çalışmada elde edilen bulguyla paralel ve çalışmadaki bulguyu destekleyen bir bulgudur. Yine başka bir çalışmada Koçak (2016) duygusal tükenmişlik alt boyutunda lise öğrencilerinin barınma değişkenine göre okul tükenmişliğinin farklılaşmakta olduğu ve pansiyondaki öğrencilerin ailenin yanındakilere göre daha düşük okul tükenmişliği ortalamasına sahip olduğu sonucunu elde etmiştir. Bu bulgu da çalışmada elde edilen bulguyu desteklemektedir. Tümkaya ve Çavuşoğlu (2010) ise yaptıkları çalışmalarında sınıf öğretmenliği öğrencilerinin yaşadığı tükenmişliğin barınma yerine göre anlamlı olarak farklılaşmadı̆̆ı sonucunu elde etmişlerdir. Bu bulguysa çalışmada ulaşılan bulguyla çelişen bir bulgudur. Bu çalışmada ve daha önceki çalışmalarda ulaşılan sonuçlara dayanılarak; liseye yatılı devam etmekte olan öğrencilerin okulla ilgili çeşitli süreçlere daha çok alıştığından kaynaklı daha az okul tükenmişliği yaşamakta oldukları yorumu yapılabilir. Ayrıca ailesinin yanında eğitim hayatına devam eden öğrencilere ailenin okulla ilgili beklentileri sorgulaması ve çeşitli sorumlulukları yerine getirmesini istemesinin de gündüzlü olarak liseye devam edenlerin okul tükenmişliğini daha çok yaşamalarına bir sebep olarak gösterilebilir.

Çalışmada lise öğrencilerinin okul tükenmişliğinin sınıf seviyesine göre farklılaşıp farklılaşmadığı incelenmiştir. Üç alt boyutta da sınıf seviyesine göre okul tükenmişliğinin farklılaştığı ve sınıf seviyesi yükseldikçe okul tükenmişliğinin de artmakta olduğu sonucuna ulaşılmıştır. Çalışmada elde edilen bulgunun literatürdeki başka çalışmalarla tutarlı olduğu görülmektedir (Addis, 2006; Kutsal, 2009; Balkıs ve diğ., 2011; Gündüz ve diğ., 2012; Kutsal ve Bilge, 2012; Çapulcuoğlu ve Gündüz, 2013; Koçak, 2016). Çalışmada elde edilen sonuca göre; sınıf seviyesi arttıkça okul tükenmişliğinin artmasında öğrencilerin mezuniyete yaklaştıkça sınav süreçlerinden kaynaklı artan sorumlukların, ailenin ve çevrenin beklentilerinin etkili olduğu söylenebilir.

Çalışmada cevap aranan diğer bir soru ise sosyal desteğin okul tükenmişliğinin anlamlı bir yordayıcısı olup olmadığıdır. Sosyal destekle 
okul tükenmişliği arasında negatif yönlü ve anlamlı bir ilişki olduğu sonucuna ulaşılmıştır. Daha sonra sosyal desteğin aileden sosyal destek ve arkadaştan sosyal destek alt boyutlarının okul tükenmişliğinin 3 alt boyutunun da anlamlı birer yordayıcısı olduğu sonucuna ulaşılmıştır. Özel bir insandan destek alt boyutu ise okul tükenmişliğinin anlamlı bir yordayıcısı olmadığı bulunmuştur. Bu bulguya göre aslında aile ve arkadaş çevresinin okul tükenmişliğini azaltıcı etkisi olduğu özel bir insanın desteğininse çok da etkisi olmadığı yorumu yapılabilir. Çalışmada elde edilen sosyal desteğin okul tükenmişliğini yordayıcı olması sonucunu destekleyen çalışmalar bulunmaktadır (Jacobs ve Dodd, 2003; Kovach, 2002; Pazin, 2000; Weaver, 2000, Kutsal ve Bilge, 2012; Çam, Deniz ve Kurnaz, 2014; Meylan, Doudin, Curchod-Diedi ve Stephan, 2015). Cohen ve Wills'e (1985) göre sosyal destek bireylerin yaşadığı stresli durumları azaltıcı ve stresle başa çımakta yardımcı bir rol üstlenmektedir. Kim ve ark. (2017) göre de stresli bir durumda soyal destek bireylere o durumun üstesinden gelmekte yardım etmektedir. Okul ortamındaki öğrencilerde görülen ve stresli bir durum olan okul tükenmişliği için de sosyal desteğin azaltıcı bir etkisi olduğu söylenebilir. Bu çalışmadan ve önceki yapılan çalışmalardan elde edilen bulgular sosyal desteğin okul tükenmişliğini azaltıcı bir role sahip olduğunu göstermektedir. Okul tükenmişliği yaşamakta olan öğrencilerin aile, öğretmen veya çevresinde kendine yardımcı olan birinin desteğinin bu olumsuzlukla başa çıkmasında etkili olduğu söylenebilir (Kutsal ve Bilge, 2012).

Bu çalışmada okul tükenmişliğini kızların erkeklere nazaran daha çok yaşadığı sonucuna ulaşılmıştır. Bu bulgu ışığında kız öğrencilerden ebeveynlerin, öğretmenlerin ve çevrenin okul yaşantısıyla ilgili makul beklentiler içerisinde olması ve kız öğrencilere fazla roller yüklememesi önerilmektedir. Çalışmada elde edilen diğer bir sonuç lise eğitimine gündüzlü olarak devam eden bireylerin yatılı olanlara göre daha fazla okul tükenmişliği yaşadığıdır. Bu sonuç ışığında; ebeveynlerin ve bireye yakın olan aile üyelerinin bireylerden okul süreci konusunda yüksek beklenti içerisine girmemesi ve okul süreci ile ilgili bireyleri destekleyici bir tavır takınmaları önerilmektedir. Çalışmada başka bir sonuçta da okul tükenmişliğin sınıf seviyesi artıkça artmakta olduğu bulgusudur. Sınav sürecine yaklaşan bireylere destek olunması ve sınav sürecinin olumsuz etkilerini azaltıcı çalışmaların yapılması önerilmektedir. Çalışmanın bir 
diğer sonucu da sosyal desteğin okul tükenmişliğiyle negatif ilişkiye sahip olması ve okul tükenmişliğini azaltıcı bir role sahip olduğudur. Bu sonuca göre okul sürecine devam eden bireylerin bu süreci daha az stresli ve kaygılı geçirmelerini böylece de daha az okul tükenmişliği yaşamalarını sağlamak için sosyal çevrenin öğrencilerden desteğini esirgememesi, güdüleyici bir yaklaşım sergilemesi ve bireylere destek olması önerilmektedir. Ayrıca bireylerin okul süreciyle ilgili yaşadığı problemleri rahat bir şekilde ifade edebilmesi için sosyal destek kaynakları olan aile, öğretmen ve arkadaş çevresinin öğrencileri anlayış ve hoşgörü ile karşılayıp, etkili iletişim kurmalarının gerekli olduğu önerilmektedir.

$\mathrm{Bu}$ çalışmanın bazı sınırlıkları bulunmaktadır. İlk olarak çalışma sadece Niğde ilinde eğitim öğrenimlerine devam eden lise öğrencileri üzerinde yürütülmüştür. Yeni çalışmalarda farklı illerden ve farklı kademede eğitim öğrenimine devam eden öğrencilerin de çalışmaya dahil edilmesinin bu sinırlılığı azaltacağı düşünülmektedir. Diğer bir sinırlılıksa çalışmada elde edilen bulgular öğrencilerin doldurduğu öz bildirime dayalı ölçme araçlarıyla elde edilmiştir. Yeni yürütülecek çalışmalarda gözlem, görüşme gibi veri toplama yöntemleriyle de verilerin elde edilmesinin geçerliği ve güvenirliği daha yüksek olan sonuçlar elde edilmesine katkı sağlayacağı ön görülmektedir. 
EXTENDED ABSTRACT

\title{
Examination of School Burnout of High School Students in Terms of Social Support and Various Factors
}

\author{
* \\ Selim Gündoğan \\ Ömer Halisdemir University
}

Burnout has emerged as a condition seen in individuals in business life. The concept of burnout has been the subject of research since the 1970s (Pines and Nunes, 2003). The concept of burnout was first defined by Freudenberger (1974) as a situation that occurs as a period of intense fatigue or boredom with the increase in demand for energy, power and resources. Later, it was suggested by researchers that the concept of burnout was not only a concept related to work life but also emerged in school life and the concept of school burnout was introduced into the literature (Schaufeli et al., 2002; Gan and Shang, 2007; Zhang, Gan and Cham, 2007; Salmela-Aro, Kiuru, Leskinen and Nurmi, 2009; Parker and Salmela-Aro, 2011, Çapri, Gündüz and Gökçakan, 2011; Aypay, 2011; Holy and Wise, 2012; Seçer and Gençdoğan, 2012). The concept of school burnout is defined as the intense expectations of the school and the education life in general, that the students wear and tear the students emotionally, cognitively and physically (Aypay and Eryılmaz 2011; Salmela-Aro, Kiuru, Leskinen and Nurmi, 2009).

Research has shown that school burnout in students is affected by many concepts and related to many concepts. One of the external factors affecting school burnout is social support. There are studies examining the relationship between social support and school burnout (Pazin, 2000; Weaver, 2000, Kovach, 2002; Jacobs and Dodd, 2003; Sacred and Wise, 2012; Pine, Sea and Cunning, 2014). The theoretical basis of the concept of social support is based on Kurt Lewin's Field Theory and definition of behavior (Boldwin, 1967; Act. Yıldırım, 1998). The concept of social support; an honest and empathic response from an individual's environment, attention, 
love, trust, respect, appreciation, information and financial aid, such as personal, social, psychological and economic quality is defined as any kind of help process (Yildirım, 2010). According to Sacred and Bilge (2012), the student's own power and wishes, as well as his/her family, friends, teachers' balanced expectations, support and guidance of the close environment are also important factors in burnout seen in students. These factors play a role in reducing school burnout. In other words, increasing social support decreases school burnout and leads to a more productive life of the student (Kim et al., 2017). As a result, it is seen that school burnout is a common situation among students with negative effects on many characteristics of students. It is seen that one of the concepts that have a negative relationship with school burnout and have a role to reduce school burnout is social support in the related literature (Jacobs and Dodd, 2003; Kutsal and Bilge, 2012; Çam, Deniz and Kurnaz, 2014).

This study sought to answer the following questions:

- Do high school students' burnout scores differ significantly by gender, grade and high school reading or boarding variables?

- Is there a significant relationship between school burnout scores and social support levels of high school students?

- Is the social support of high students' school burnout a significant predictor?

The study was conducted in the survey model. The universe of the study consists of 19233 high school students who continue their high school education in Niğde. The sample consisted of 348 high school students (195 girls and 153 boys) attending various high schools. Data were collected by Salmela-Aro et al. (2009) and developed by Seçer et al. (2013) adapted to Turkish by the school burnout scale, Zimet et al. (1988), which was developed by Eker, Arkar and Yaldız (2001) and collected by the Turkish culture by the Multidimensional Perceived Social Support Scale and the personal information form prepared by the researcher.

The data were analyzed by using $t$ test, ANOVA, correlation and regression analyzes. The normal distribution of data, which is a prerequisite for parametric tests, was checked by examining the kurtosis and skewness coefficients. Coefficient of kurtosis and skewness were .633 and .161 for emotional exhaustion, .773 and -.395 for depersonalization, .767 and -.223 for low personal achievement perception, -.287 and -.236 for social support 
from a special person, social from family -.766 and -.562 for support, -.641 and -.569 for social support from friends. Data were normally distributed and then the analysis phase was passed (Büyüköztürk, 2007). In addition, the effect sizes of the data were calculated by eta-square ( $\eta 2)$ and Cohen's $\mathrm{d}$ index.

As a result of $\mathrm{T}$ test analysis, it was found that school burnout differed in favor of girls in emotional exhaustion and low personal achievement sub-dimensions according to gender variable. It was found that school burnout differed in favor of daytime students in all three sub-dimensions according to the boarding or daytime reading variable. According to the ANOVA analysis according to the class variable, it was found that school burnout differed in all three sub-dimensions. Regression analysis was conducted to determine the relationship between school burnout and social support. It is concluded that social support is a significant predictor of school burnout.

This study has some limitations. Firstly, the study was conducted only on high school students continuing their education in Niğde. It is thought that the inclusion of students from different provinces and different levels of education in new studies will reduce this limitation. Another limitation was the findings obtained from the study with self-reported measurement tools. In the studies to be conducted, it is foreseen that data collection methods such as observation and interview will contribute to the results with higher reliability and validity.

\section{Kaynakça / References}

Acar, H. ve Çakır, M.A. (2015). Lise öğrencilerinin tükenmişlik düzeylerinin incelenmesi: Yeşilova ilçesi örneği. Mehmet Akif Ersoy Üniversitesi Ĕ̆itim Fakültesi Dergisi, 34,152 -168.

Addis, R.S. (2006). Burnout among undergraduate athletic training students. Masters's Dissertation, California University, U.S.A.

Akpınar, M. (2016). Okul tükenmişliği ile akademik stres ve öznel iyi oluş arasındaki ilişkinin incelenmesi (Yayımlanmamış yüksek lisans tezi). Atatürk Üniversitesi/Eğitim Bilimleri Enstitüsü, Erzurum. 
Aypay, A. (2011). İlköğretim II. kademe öğrencileri için okul tükenmişliği ölçeği: Geçerlik ve güvenirlik çalışması. Kuram ve Uygulamada Eğitim Bilimleri, 11(2), 511-527.

Aypay, A. ve Eryılmaz, A. (2011). Lise öğrencilerinin derse katılmaya motive olmaları ile okul tükenmişliği arasındaki ilişkinin incelenmesi. Mehmet Akif Ersoy Üniversitesi Ĕ̆itim Fakültesi Dergisi, 11 (21), 26-44.

Aypay, A. ve Sever, M. (2015). School as if a workplace: Exploring burnout among high schoolstudents. Journal of Theory and Practice in Education, 11(2), 460-472.

Büyüköztürk, Ş. (2007). Sosyal bilimler için veri analizi el kitabı. Ankara: Pegem A Yayincilik

Büyüköztürk, Ş., Kılıç-Çakmak, E., Akgün, Ö. E., Karadeniz, Ş. ve Demirel, F. (2014). Bilimsel araştırma yöntemleri (17.baskı). Ankara: Pegem.

Çakmak, A. ve Şahin, H. (2017). Ortaokula devam eden öğrencilerin algıladıkları sosyal desteğin okul tükenmişliğine etkisinin incelenmesi. Elektronik Sosyal Bilimler Dergisi, 16(61), 568-582.

Çam, Z., Deniz, K. Z. ve Kurnaz, A. (2014). Okul tükenmişliği: algılanan sosyal destek, mükemmeliyetçilik ve stres değişkenlerine dayalı bir yapısal eşitlik modeli sinaması. Ĕ̆itim ve Bilim, 39 (173), 312-327.

Çapri, B., Gündüz, B. ve Gökçakan, Z. (2011). Maslach tükenmişlik envanteriöğrenci formu'nun (mte-öf) Türkçe'ye uyarlaması geçerlik ve güvenirlik çalışması. Çukurova Üniversitesi Ĕ̆itim Fakültesi Dergisi. 40 (1), 134-147.

Çapulcuoğlu, U. ve Gündüz, B. (2013). Öğrenci tükenmişliğini yordamada stresle başa çıkma, sınav kaygısı, akademik yetkinlik ve anne-baba tutumları. Ĕ̆itim Bilimleri Araştırmaları Dergisi, 3(1), 202-218.

Cohen, S. ve Wills, T.A. (1985). Stres, social support and the buffering hypothesis. Psychological Bultening, 92, 257-310.

Cohen, S., ve Syme, S. L. (Eds.). (1985). Social support and health. San Diego, CA, US: Academic Press.

Demir, M. (2015). Okul tükenmişliğinin yordanmasında sınav kaygısı ve akademik başarının etkisi. Yayımlanmamış Yüksek lisans tezi. Atatürk Üniversitesi/ Eğitim Bilimleri Enstitüsü, Erzurum.

Demirel, Z. (2018). Özel yetenekli ortaokul öğrencilerinin okul tükenmişliğinin çeşitli değişkenler açısından incelenmesi. Yayımlanmamış yüksek lisans tezi. İstanbul Sabahattin Zaim Üniversitesi, Sosyal Bilimler Enstitüsü, İstanbul. 
Eker, D., Arkar, H. ve Yaldız, H. (2001). Çok boyutlu algılanan sosyal destek ölçeği'nin gözden geçirilmiş formu'nun factor yapısı, geçerlik ve güvenirliği. Türk Psikiyatri Dergisi, 12 (1), 17-25.

Erkuş, A. (2005). Bilimsel araştırma sarmalı. Ankara: Seçkin Yayıncılık

Firth, H., Micntee, J., Mckown, P., ve Britton, P. G. (1985). Maslach burnout inventory: factor structure and norms for british nursing staff. Psychological Report, 57, 147-150.

Freudenberger, H. J. (1974). Staff burnout. Journal of Social Issue, 30, 159-165.

Friesen, D. ve Sarros, J.C. (1989). Sources of burnout among educators. Journal of Organizational Behavior, 10 (2), 179-188.

Gan, Y., ve Shang, J. (2007). Coping flexibility and locus of control as predictors of burnout among chinese college students. Social Behavior and Personality, 35, 1087-1098. doi:10.2224/sbp.2007.-35.8.1087

Gündüz, B.,Çapri, B. ve Gökçakan, Z. (2012). Üniversite öğrencilerinin tükenmişlik düzeylerinin incelenmesi. Dicle Üniversitesi Ziya Gökalp Eğitim Fakültesi Dergisi, 19, 38-55.

Jackson, S. E., Schwab, R. L., ve Schuler, R. S. (1986). Toward an understanding of the burnout phenomenon. Journal of Applied Psychology, 71(4), 630-640.

Jacobs, S. R. ve Dodd, D. (2003). Student burnout as a function of personality, social support, and workload. Journal of College Student Development, 44(3), 291-303

Kaçmaz, N. (2005). Tükenmişlik (Burnout) sendromu. İstanbul Tıp Fakültesi Dergisi, 68(1), 29-32.

Kim, B., Jee, S., Lee, J., An, S. ve Lee, S.M (2017). Relationships between social support and student burnout: A meta-analytic approach. Stress and Health, 3,127-134. doi: 10.1002/smi.2771

Koçak, L. (2016). Lise öğrencilerinde okul tükenmişliği ile depresif belirtiler arasındaki ilişkinin incelenmesi. Yayımlanmamış yüksek lisans tezi. Atatürk Üniversitesi,Eğitim Bilimleri Enstitüsü, Erzurum.

Koçak, L. ve Seçer, İ. (2018). Lise öğrencilerinde okul tükenmişliği ile depresyon ve kaygı arasındaki ilişkinin incelenmesi. Çukurova Üniversitesi Ĕ̆itim Fakültesi Dergisi, 47(2). 601-622.

Kovach, H. R. (2002). Relationship Among Stress, Social Support And Burnout Counseling Psychology Graduate Students. Doctoral Dissertation, University Missouri-Kansas City, U.S.A. 
Kutsal, D ve Bilge, F. (2012). Lise öğrencilerinin tükenmişlik ve sosyal destek düzeyleri. Eğitim ve Bilim, 37 (164), 283-297.

Kutsal, D. (2009). Lise öğrencilerinin tükenmişliklerinin incelenmesi. Yayımlanmamış yüksek lisans tezi. Hacettepe Üniversitesi,Sosyal Bilimleri Enstitüsü, Ankara.

Lahoz, M. R., ve Mason, H. L. (1989). Maslach burnout inventory: factor structure and norms for USA pharmacists. Psychological Report, 64, 10591063.

Luo, Y., Wang, Z., Zhang, H. ve Chen, A. (2016). The influence of family socioeconomic status on learning burnout in adolescents: mediating and moderating effects. Journal of Child and Family Studies, 25, 2111-2119. doi:10.1007/s10826-016-0400-2

Maslach C. ve Leiter, M. P. (1997). The truth about burnout. California: JossyBass

Maslach, C. (Eds.) (1981). In The burnout syndrome (p. 30-53). Park Ridge, IL: London House.

Maslach, C. ve Jackson, S. E. (1981). The measurement of experienced burnout. Journal of Occupational Behavior, 2, 99-113.

Meylan, N., Doudin, P. A., Curchod-Diedi, D. ve Stephan, P. (2015). School burnout and social support: The importance of parent and teacher support. Psychologie Française, 60(1), 1-15.

Özbakır, E. (2015). Ortaokul öğrencilerinin insani değerleri ile okul tükenmişliği arasındaki ilişki ve bir araştırma. Yayımlanmamış yüksek lisans tezi .Beykent Üniversitesi, Eğitim Bilimleri Enstitüsü, İstanbul.

Özdemir, Y. (2015). Ortaokul öğrencilerinde okul tükenmişliği: ödev, okula bağlllık ve akademik motivasyonun rolü. Adnan Menderes Üniversitesi Eğitim Fakültesi, Eğitim Bilimleri Dergisi, 6(1), 27-35.

Özgen, H. (2016). Üniversite öğrencilerinde okul tükenmişliği ile psikolojik yardım ihtiyacı arasındaki ilişkinin incelenmesi. Yayımlanmamış yüksek lisans tezi. Atatürk Üniversitesi, Eğitim Bilimleri Enstitüsü, Erzurum.

Parker, P. D., ve Salmela-Aro, K. (2011). Developmental processes in school burnout: a comparison of major developmental models. Learning and Individual Differences, 21(2), 244-248. doi:10.1016/j.lindif.2011.01.005

Pazin, J. S. (2000). The effects of burnout on doctoral counseling students in Cacrep accredited universities. Doctoral Dissertation. U.S.A: St. Mary's University. 
Pines, A.M. ve Nunes, R. (2003). The Relationship between career and couple burnout: implications for career and couple counseling. Journal of Employment Counseling, 40 (2), 50-64.

Salmela-Aro, K. ve Tynkkynen, L. (2012). Gendered pathways in school burnout among adolescents. Journal of Adolescence, 35, 929-939.

Salmela-Aro, K., Kiuru, N., E., ve Nurmi, J. E. (2008). The role of educational track in adolescents' school burnout: A longitudinal study. British Journal of Educational Psychology, 78 (4), 663-689.

Salmela-Aro, K., Kiuru, N., Leskinen, E., ve Nurmi, J. (2009). School burnout inventory (SBI): reliability and validity. European Journal of Psychological Assessment, 25, 48-57. doi: 10.1027/1015-5759.25.1.48

Salmela-Aro, K., Kiuru, N., Pietikäinen, M., ve Jokela, J. (2008). Does school matter? the role of school context in adolescents' school-related burnout. European Psychologist, 13 (1), 12-23. doi:10.1027/1016-9040.13.1.12

Sarason, İ.G. ve Sarason, B.R. (1982). Concomitants of social support: attitudes, personality characteristics, and life experiences. Joumal of Personality, 50(3),331-344

Sarıcam, H. (2015). Mediating role of self efficacy on the relationship between subjective vitality and school burnout in turkish adolescents. Educational Research Association The International Journal of Educational Researchers, $6(1), 1-12$.

Schaufeli, W. B., Martìnez, I. M., Pinto, A. M., Salanova, M. ve Bakker, A. B. (2002). Burnout and engagement in university students: A cross-national study. Journal of Cross-cultural Psychology, 33(5), 464-481.

Seçer, İ. (2015). Üniversite öğrencilerinde okul tükenmişliği ile psikolojik uyumsuzluk arasındaki ilişkinin incelenmesi. Atatürk Üniversitesi Sosyal Bilimler Enstitüsü Dergisi, 19 (1), 81-99.

Seçer, İ. ve Gençdoğan, B. (2012). Ortaöğretim öğrencilerinde okul tükenmişliğinin çeşitli değişkenler açısından incelenmesi. Turkish Journal of Education, 1(2), 1- 13.

Seçer, İ., Halmatov, S., Veyis, F. ve Ateş, B. (2013). Okul tükenmişlik ölçeğinin Türkçe'ye uyarlanması: güvenirlik ve geçerlik çalışması. Turkish Journal of Education (Türk Eğitim Dergisi), 2 (2), 16-27.

Şeker, G. ve Yavuzer, Y. (2017). Ergenlerde okul tükenmişliğinin yordayıcısı olarak akademik kontrol odağı. Mersin Üniversitesi Eğitim Fakültesi Dergisi, 13(3), 919-935. doi: 10.17860/mersinefd.299266 
Sorias, (1988). Sosyal destek kavramı. Ege Üniversitesi Tıp Fakültesi Dergisi, 2 (1), 353-357.

Tardy, C. (1985). Social support measurement. American Journal of Community Psychology, 113(2), 187-202.

Torun, A. (1997). Stres ve tükenmişlik. (S. Tevrüz Ed.). (2. Bsm), Endüstri ve Örgüt Psikolojisi içinde (43-53), İstanbul: Türk Psikologlar Derneği ve Kalite Derneği Ortak Yayını,

Tümkaya, S. ve Çavuşoğlu, İ. (2010). Sınıf öğretmenliği son sınıf öğretmen adaylarının tükenmişlik düzeylerinin incelenmesi. Çukurova Üniversitesi Sosyal Bilimler Enstitüsü Dergisi, 19 (2), 468- 481.

Weaver, K.L. (2000). Burnout, Stress and Social Support Among Doctoral Students In Psychology, Doctoral Dissertation, U.S.A.: West Virginia University.

Yıldırım, İ. (1998). Akademik başarı düzeyleri farklı lise öğrencilerinin bazı değişkenlere göre sosyal destek düzeyleri. Türk Psikolojik Danışma ve Rehberlik Dergisi. 10(2). 33-45.

Yıldırım, İ. (2010). Anne-baba desteği ve başarı: Anne-babalar çocuklarına nasıl destek olabilirler? (2. Bask1), Ankara: Anı Yayıncılık.

Zhang, Y., Gan, Y., ve Cham, H. (2007). Perfectionism, academic burnout and engagement Chinese college students: A structural equation modeling analysis. Personality and Individual Differences, 43(6), 1529-1540. doi: 10.1016/j.paid.2007.04.010

\section{Kaynakça Bilgisi / Citation Information}

Gündoğan, S. (2019). Lise öğrencilerinin okul tükenmişliklerinin sosyal destek ve çeşitli değişkenler açısından incelenmesi. OPUSUluslararası Toplum Araştırmaları Dergisi, 13(19), 25-49. DOI: 10.26466/opus.552366 